\title{
Research on The Developmental Aspects of The Steam Education Program Development in Korea
}

\author{
Seungyon-Seny Lee \\ Professor, Graduate School of Culture Technology, SangMyung University, Kore \\ senylee01@gmail.com
}

\begin{abstract}
This study examines the types of STEAM education programs through its development in Korea and the direction in which Korean creative education research focuses based on ICT in the fourth industrial era. The preliminary data of this study were investigated based on KOFAC's proposal request, and the development pattern by year and type from 2012 to 2020 is analyzed. The STEAM education program development maintains three basic types, and the other types are subtle but attempt to change in education development by presenting new fields every year. The three basic types are: Interdisciplinary Subject Integration Advanced Products Utilization and Science-Arts Convergence. Based on the development process in the subject area according to each type, the characteristics and relationships of the type are examined, and the link between the development of science and technology and social phenomenon is confirmed. As a researcher who continuously participated in the STEAM education project, the purpose is to analyze the linkage between the types and to suggest the direction of STEAM education development in Korean education in the future.
\end{abstract}

Keywords: The Types of STEAM Education, Development Aspects, Interdisciplinary Subject

Seungyon-Seny Lee

Professor, Graduate School of Culture Technology,

SangMyung University, Kore

senylee01@gmail.com
Integration, Advanced Products Utilization, ScienceArts Convergence

\section{Introduction}

Research Purpose

STEM education in Korea appears as a STEAM education that emphasizes creativity by adding the 'A' domain of art and humanities. In terms of fostering creative convergence talent, the claim that arts should be included in STEM often appears in many respects because the creativity of art is regarded just as significant as science [1]. The Korea Foundation for the Advancement of Science and Creativity(KOFAC) [2], an agency affiliated with the Ministry of Science and Technology of Korea, first conspired to develop a Korean STEAM education program as a project task in 2012. The data was analyzed based on the project's proposal request. KOFAC has changed the types of assignments since 2019. As a researcher who participated in the task development more than 6 times, it is meaningful to recognize the need for the future direction of Korean STEAM education at this point and organize the development patterns of STEAM education program development that has been achieved over the past 8 years.

\section{Background Of Steam Education In Korea}

The United States mainly emphasizes STEM education, but STEAM education in the United States intends to be globally competitive in mathematics and 
science education by integrating engineering, technology, and art into the existing mathematics and science education [3]. In particular, 'A' intends to strengthen innovative creativity and flexibility by intentionally connecting design or creative art to STEM education. STEAM was created to broaden interest in science and technology, but some indicate that it fails to acknowledge the exploration and understanding of the principles of science and technology itself. However, this is the case for teaching science subjects by simply introducing concepts and connecting science subjects to singing or drawing activities. In the early stages of the development of STEAM in Korea, teachers often lacked the concept of linkage or integration between themes. In many cases, since the theme belonged to a certain subject, it was difficult for teachers to explore or integrate different subject elements to apply in different fields [4].

KOFAC announced its first project task in June 2012, and in November of the same year, announced the second. From then on, the project task was promoted once a year until 2020, and a total of 10 projects were held. This paper focuses on the types of development fields and topics of those types that have been conducted for 10 times and investigates them in three main ways. First, it examines the linkage of subtopics of the development field type by year and examines the interrelationships and characteristics of the development process. There are four types of development fields: 1 < Interdisciplinary Subject Integration $>$, (2) $<$ Advanced Products Utilization $>$, (3) $<$ Science-Arts Convergence $>$, and (4) $<$ Future Career Connection $>$. The Type of $<$ Future Career Connection> appeared in 2013 and maintained with three other types until 2019 but disappeared in 2020 [5]. This paper will examine only two types related to ICT-oriented scientific technology, which are $<$ Interdisciplinary Subject Integration $>$ and $<$ Advanced Products Utilization $>$. Second, based on the analysis of these two types, the connection or interaction between ICT-centered scientific technology and social issues will be examined. Third, the strengths and weaknesses of STEAM education will be explored through typology analysis, and future sustainable directions will be predicted and suggested.

\subsection{Changes In Korea Steam Program By Sectoral} Types And Years

The development of the STEAM education program demanded by KOFAC in 2012 suggests that students should be able to cultivate convergent thinking and problem-solving skills as well as have fun and interest in science and technology [6]. Based on these objectives, additional categories can be found after 2015. 'Integrated thinking' in the existing purpose has added creativity to 'creative and integrated thinking', which gives the intention of amplifying creative interpretation by giving scientific grounds interpreted as philosophical concepts or aesthetics in the field of humanities and arts, rather than applying scientific principles. In addition, the byword STEAM education has a long predicate that reminds of the clear purpose, 'for the development of various future-oriented programs'. It does not seem to be a scientific principle or an obsolete technology but seems to require the creation of productive values that can be used and applied in real life.

(1) (2) and (3), the three sectoral types, at the beginning of the project will continue on in the context of large basic types by 2020. In the first half of 2012, the program development in three fields that constitute the basic axis is (1) $<$ Subject Integration in Science and Technology $>$, (2) $<$ Advanced Products Utilization>, and (3) < Science-Arts Convergence $>$. However, in the second half of 2012, (3) $<$ ScienceArts Convergence $>$ is maintaine and is divided into $<$ STEAM for Technology Teacher $>$ and $<$ STEAM for Art Teacher $>$ [7]. Neither (1) Subject Integration in Science and Technology> nor (2) <Advanced Products Utilization $>$, it was odd to require education development by classification according to teachers and not the same subject type, but this was soon identified. It is speculated that in the early stages of STEAM education because the teachers were having difficulty deducing a convergent perspective, the intention may have been to ask teachers in each subject to demand a lesson plan for the purpose of basic understanding. As expected, this teacheroriented development has since disappeared and cannot be found to date.

KOFAC, which presented a somewhat experimental type in the second half of 2012, required development based on a total of four types from 2013 to 2019. The three types of (1) (2) (3) in the first half of 2012 were observed, and (4) a new type, $<$ Designbased Prospective Career $>$ was added. Since 2013 was the first time 3D-printers were introduced in Korea, it demanded the productivity department to 
create something practical based on the design by utilizing facilities such as Makers and Idea Factory. As students create and understand, the process of understanding is important, and in the process of thinking through design, they learn that the feedback of colleagues can improve the problem. KOFAC would have predicted that students may receive various related careers through the experience of the manufacturing practice.

Designated as the main program in 2012-13 (1) $<$ Interdisciplinary Subject Integration in Science and Technology $>$ changed its name in 2014 to $<$ Interdisciplinary Subject Integration in Academia> and remains to this day. This name change can be seen as a purpose to reinterpret the basic principles of science and technology within a large academic framework and to understand them from different perspectives. (4) Proposed in 2013, <Design-based Prospective Career $>$ remains in place under the name of $<$ Future Career Connection $>$ from 2014 to 2019. It can be viewed from two perspectives for reasons behind the suggestion of future careers. First, it is not to encourage learning that is lost with knowledge but to encourage the connection of applicable creative learning. Second, the rapid rise of major science and technology representing the fourth industrial revolution, such as AI, IoT, Big Data, and Mixed Reality is the factor. By 2020, there will be 2 million jobs in this field, as $65 \%$ of children currently entering primary school will be engaged in entirely new types of jobs that do not exist today [8]. Therefore, it is interpreted as the purpose of grasping the status of research in science and technology and seeking entrepreneurship and research-related start-ups. The four types, (1) (2) (3) (4), will maintain their structure from 2014 to 2019.

\section{Sub-topics Of Type (1) <interdisciplinary Subject Integration>}

\subsection{Comparison Of Sub-topics In 2012-14}

In 2012-13, the type <Interdisciplinary Subject Integration in Science and Technology $>$ was changed to <Interdisciplinary Subject Integration in Academia $>$ in 2014, but the overall topic has a clear similarity in terms of science and technology. The topic presented at the beginning of educational development is somewhat discursive, but over the years, a close connection with social issues is found. As shown in [Table 1], organized to see the topics presented by year, has four big contexts: ICT, Bio, Sports Science, and Energy.

First, the topic of IT and Smart Device in 2012 is a preparation stage to explore the ICT domain in advance. ICT is an essential topic foreshadowing the emergence of the 4th Industrial Revolution in 2016. ICT, which specifically describes sub-topics such as internet, IoT, IoE, Big Data, Informatics, etc., is intended to deeply illuminate other areas of science and technology in consideration of the 4th Industrial Revolution. In terms of educational content, it is necessary to grasp the current status of industrial technology and to design future careers.

Second, Bio also has many common features with Sports Science, which is noticeable by examining specific topics such as Bio Informatics, Brain Science, disease, Lifespan, Health, etc. presented in 2014. When examining sports science from the perspective of bio, not only is a scientific exploration of the human body connected to sports, but scientific well-being can also be designed by liking the social structure of the near future leading to aging and smart healthcare. In addition, the medical technology and rehabilitation environment in connection with prosthetic devices or robot technology can be designed by tying the specificities of the disabled and athletes with bio in the human-centered level.

Third, Energy is not necessarily an essential energy resource, but rather a deep environmental problem. In the energy classification of 2014, specific research directions related to the environment such as alternative energy, energy management, energy efficiency, energy storage, and energy transfer, RFID are identified.

Table 1 is categorized based on a sub-topic in 2012. As noted in the above footnote*, the sub-topics of (a) and (b) in each task code cannot be selected separately and is to be proceeded as one task. The classification of topics according to the linkages in the field of science and technology was reclassified and analyzed in Table 2 since the regulations are maintained in the 2013 project. It is clear that developing with these group-specific topic choices places many limitations on researchers.

In 2013, the free topic in footnote ** is still difficult to self-configured because of its limits on intensifying or expanding only on the topic (a). As a 
Table 1 : The Sub-Topics Classification of <Interdisciplinary Subject Integration in Science and Technology $>$ in 2012-14

\begin{tabular}{|c|c|c|c|c|}
\hline $\begin{array}{l}\text { Project } \\
\text { code }\end{array}$ & 2012 Sub-Topics* & 2013 Sub-Topics* & $\begin{array}{l}\text { Project } \\
\text { code }\end{array}$ & 2014 Sub-Topics \\
\hline \multirow{2}{*}{$1-1$} & (a)LED & (a)LED & & \\
\hline & (b) IT & (b) ICT & $1-1$ & ICT: internet, IoT, IoE, BigData, Informatics, etc \\
\hline \multirow{2}{*}{$1-2$} & (a) Bio & (a) Bio & $1-4$ & Bio: Bio Informatics, Brain Science, disease, Lifespan, Health, etc \\
\hline & (b) Sports Science & (b) Sports Science & $1-5$ & Sports Science \\
\hline \multirow{3}{*}{$1-3$} & (a) Energy & (a) Energy & & Energy: alternative energy, energy management, energy efficiency, energy \\
\hline & & & & storage, energy transfer (RFID etc) \\
\hline & (b) media & (b) related free topics ${ }^{* *}$ & $1-10$ & $<$ Interdisciplinary Subject Integration in Science and Technology $>$ Free topic ${ }^{* * *}$ \\
\hline \multirow[b]{2}{*}{$1-4$} & (a) digital & (a) Space exploration & $1-2$ & Aerospace \\
\hline & (b) future Mass media & (b) New Material & $1-9$ & $\begin{array}{l}\text { Future Manufacturing Technologies: 3D Printing, Laser Cutter, } \\
\text { Microfabrication Technology }\end{array}$ \\
\hline \multirow{3}{*}{$1-5$} & & (a) climatic change & $1-3$ & $\begin{array}{l}\text { Global Environment: ocean(abyss, the pole), shale gas, global warming, } \\
\text { climatic change, water deficit, desertification, etc }\end{array}$ \\
\hline & (a) design & & $1-7$ & Robot, mechanical engineering \\
\hline & $\begin{array}{l}\text { (b) smart device } \\
\text { (except smartphone or TV) }\end{array}$ & & $1-8$ & $\begin{array}{l}\text { Ergonomics: Cognitive Engineering, Virtual Reality, Network, Emotional } \\
\text { Design }\end{array}$ \\
\hline
\end{tabular}

* 2012/2013: Research projects can only be applied in units of task codes, and cannot be applied for topics by unit (Development of each (a) (b) subject defined in the task code)

** 2013: (a) Composed of free topics related to the concept of deepening or expanding on the energy topics. *** 2014: Free Subjects are free to present tasks that are appropriate to the field.

Table 3 : Descriptive statistics on reading attitude, strategy, and motivation

\begin{tabular}{|c|c|c|}
\hline 2012 & 2013 & 2014 \\
\hline Bio & Bio & Bio: Bio Informatics, Brain Science, disease, Lifespan, Health, etc \\
\hline Sports Science & Sports Science & Sports Science \\
\hline Energy & Energy & $\begin{array}{l}\text { Energy: alternative energy, energy management, energy efficiency, energy } \\
\text { storage, energy transfer (RFID etc) }\end{array}$ \\
\hline \multirow{3}{*}{$\begin{array}{l}\text { IT/smart device } \\
\text { (except smartphone or TV) }\end{array}$} & ICT & ICT: internet, IoT, IoE, BigData, Informatics, etc \\
\hline & space exploration & Aerospace \\
\hline & $\begin{array}{l}\text { climatic change } \\
\text { /water deficit }\end{array}$ & $\begin{array}{l}\text { Global Environment : ocean(abyss, the pole), climatic change, water deficit, } \\
\text { shale gas, global warming, desertification, etc }\end{array}$ \\
\hline \multirow[t]{2}{*}{ LED } & LED & \\
\hline & New Material & $\begin{array}{l}\text { Future Manufacturing Technologies: 3D Printing, Laser Cutter, } \\
\text { Microfabrication Technology }\end{array}$ \\
\hline \multirow[t]{2}{*}{ design, digital } & & $\begin{array}{l}\text { Ergonomics: Cognitive Engineering, Virtual Reality, Network, Emotional } \\
\text { Design }\end{array}$ \\
\hline & Related Free topic ${ }^{* *}$ & $<$ Interdisciplinary Subject Integration in Science and Technology $>$ Free topic ${ }^{* * *}$ \\
\hline Future Mass media, media & & \\
\hline
\end{tabular}


countermeasure against these regulations, in 2014, the sub-topics that were tied were reassigned one by one with a code number. Another restriction is being made by presenting detailed keywords. However, the free topic in footnote $* * *$ opens up the researchers with full autonomy of topic choice for the first time. In this respect, Table 1 was separated based on the sub-topics of 2012-13, so it was rearranged regardless of the order of topic classification in 2014.

In Table 2, the bundle of sub-topics that are grouped in two by task code from Table 1 was disassembled and re-classified according to each field of science and technology. It is hereby possible to interpret the correlations and development patterns according to the topic. In 2012, the topic of smart devices, except for smartphones and smart TVs, was relocated to ICT. In ICT, most of the parts deal with software, but when they are linked with apps that utilize smart devices, they can create more synergies when developing programs. Here, exclusion of smartphones and TVs means education is not developed in terms of hardware. In 2013, New Material can create creative productive value through the use of innovative materials in various fields of Future Manufacturing Technologies. With regards to 3D-printer, education contents can be composed of material development and application for 3D-printer output materials. In 2014, topics such as Cognitive Engineering and Virtual Reality in Ergonomics reappear in 2016 or 2018, and they appeared rather quickly. However, these two fields are linked to Design and Digital in 2012 and associated with Emotional Design of Emotional Engineering in order to conduct classes with various activities in the $<$ Science-Arts Convergence $>$ type. Media and Future Mass Media that appeared only once in 2012 are classified as obsolete keywords that are no longer covered in other fields as well as in the $<$ Interdisciplinary Subject Integration in Science and Technology $>$.

\subsection{Comparison Of Sub-topics In 2015-18}

Common sub-topics from 2012-14 to 2015 are topics related to Bio, Energy, and Space. Bio is a topic that emerges in a large context in 2015-18 and can be linked to Medical Science such as Life Science, Molecular Diagnosis, Individualized Medicine, and Infectious Disease. It can be seen that each topic, Energy and Global Environment in 2012-14, is grouped into one topic, Energy and Environment, in 2015. Furthermore, Energy insinuates Future Industry from the extended concept of Future Energy. In the same context, the keyword New Material in 2013 extends its concept to Future New Material in 2015.

Table 3 divides the topics into (c)-(g) for the subtopic types of 2015-18. In the case of (c), Spacerelated topics are divided into sub-topics. The topic of Extra Solar Planets is expanded from Space Exploration and Aerospace in 2013-14 to Extra Solar Planets, and Space Creation in 2015 and required an intensive study on the topic. In addition, the topic of Formation and Evolution of the Earth is the only topic that continues for four years in the type of $<$ Interdisciplinary Subject Integration>, and the earth is dealt in the realm of celestial bodies category and continues its context until 2018 .

Topics that have been studied for three continuous years include Formation and Evolution of the Earth, Forensic Science, and Artificial Intelligence. It is strange that the emergence of Artificial Intelligence grouped as (d) was in 2016. Although it is soon after the controversy of the game between Alpha Go and Go Player, Lee Se-dol, despite the fact that IoT is already focused on ICT in 2014, it is true that topic of Artificial Intelligence, which serves as its brain, was introduced somewhat later. Moreover, in 2015, it is even more surprising that ICT as well as Artificial Intelligence are excluded from the 10 topics. Contrastingly, the Big Data topic that emerged in 2014 was one of the eight selected topics in 2016, and it is the topic that continues until 2018, following the context of ICT.

In the case of (e, it can be seen that the topic of Infectious Disease in 2017-18 still maintains a large part, linking the context of Bio from 2012, while dealing with the diversity of the field from various angles within one topic. Of course, it is also true that its emergence is a bit late considering it was a topic that had been relevant for many years due to the footand-mouth disease(FMD) virus.

Future New Material in 2015 from $€$ is the starting point for the connection New Materials of 2013 and Future Manufacturing Technologies of 2014. In this context, Maker in 2016 be seen in continuity as 3D printer, one of the Future Manufacturing Technologies that appeared in 2014. It can be seen that program development through practical product utilization takes place in Future Manufacturing Technology, along with the Robotics Engineering in 2014 and 
Table 4 : The development Aspect of $<$ Interdisciplinary Subject Integration $>$ in 2012-18

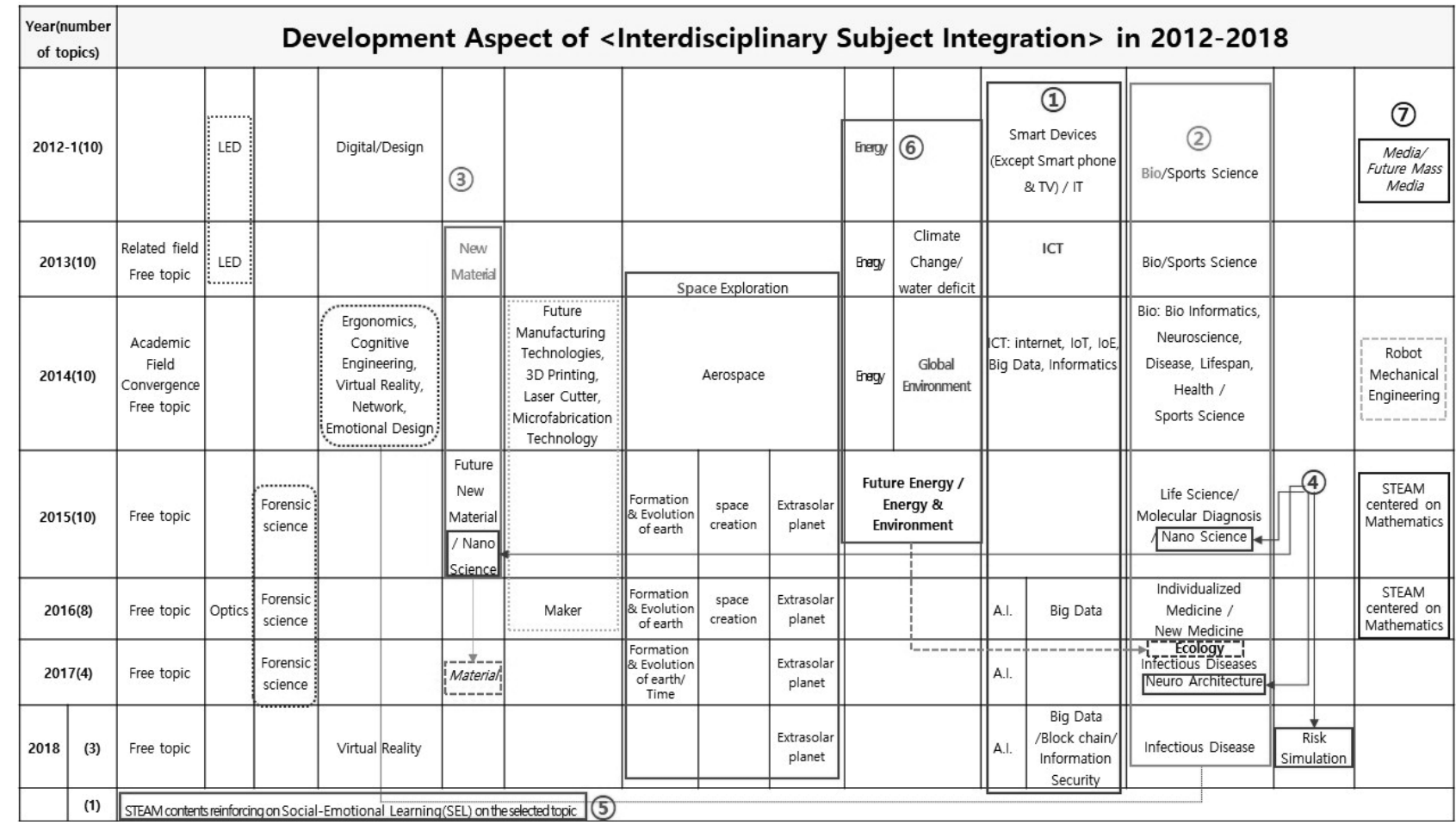

Maker in 2016 in the type of <Advanced Products Utilization>. Information Security and Blockchain, first introduced in 2018, are somewhat late in time, but the researchers developed the program with a focus on trust and security, taking into account the social problem that once caused an uproar over cryptocurrency. In addition, this topic is a staple addressed intensively in $<$ Future Career Connection $>$.

Table 4 summarizes the development direction of $<$ Interdisciplinary Subject Integration $>$ in 2012-18. First, ICT and Bio are topics that are continuously promoted from 2012 to 2018 . The correlation between these two tracks, the direction of newly emerging topics over the years, and a total of seven topics through connections between topics in academic fields and other types are examined.

First, this topic which connects smart devices with ICT, is part of a big context of artificial intelligence, big data, blockchain, and information security that lead the Fourth Industrial Revolution. Blockchain and information security are rising as the next-generation technology in terms of encryption of trust due to the emergence of virtual currency which caused a big wave towards the end of 2017.

Second, Bio, tied with sports science, was subdivided into the topics of Bio Informatics, Brain
Science, Disease, Lifespan, Health, etc., which is again merged into the topics of Life Science and Molecular Diagnosis. Selecting Life Science as the general topic, this can be connected to Individualized Medicine or New Medicine in 2016. In 2017, the focus is specified as Infectious Diseases within the topic of disease. This can be understood as to raise awareness about 'infection' based on events that occurred rural areas affected by FMD virus and the incidents caused by the spread of the virus and the immune system, such as the Middle East Respiratory Syndrome(MERS). In addition, bio-topics linked to genetic engineering should expand its scope, and program development should be elaborated, especially for medical science, disease, and new drugs.

Third, the keyword New Material is brief in its flow as it is continued into Future New Material in $<$ Interdisciplinary Subject Integration $>$. However, in $<$ Advanced Products Utilization $>$, the concept of new material is expanded to present New Advanced Products and proceeds to specific product associations such as nano, carbon, conductivity, optical fiber, and shape memory alloy. If the context of new material in the annual flow of $<$ Interdisciplinary Subject Integration $>$ is intentionally searched, it can be connected with the keyword Matter in 2017. If this flow of relevance is maintained, it would be 
appropriate for the issue of materials to emerge in 2019 in a timely perspective. However, if there is not a link between new materials and materials, the keyword would likely disappear.

Fourth, three new fields of Nanoscience, Neuroarchitecture, and Risk Simulation, appear for the first time since 2015, but disappear afterwards. Nanoscience can be viewed in two perspectives. The first perspective in which if nanoscience were viewed as nano-life scientific technology can be seen in the context of Bio. The second perspective is through the connection of New Materials, where it could be possible to connect Nano with advanced products mentioned in $<$ Advanced Products Utilization $>$. The interpretation of this perspective is how the $<$ Interdisciplinary Subject Integration $>$ is shared in many areas with the field of $<$ Advanced Products Utilization $>$. The domain can be divided according to whether it is research exploration centered on principle or theory or product application and utilization. In this manner, domains can be shared and distinguished, but other types of keywords may be adopted. Neuroarchitecture is an example. Neuroarchitecture, which first appeared as a sub-topic of the $<$ Science-Arts Convergence $>$ in 2016, was selected as a new topic in the <Interdisciplinary Subject Integration $>$ in 2017. Unlike <Advanced Product Utilization $>$ which focuses on physical properties, Neuroarchitecture focuses on nerves from the perspective of architectural trajectories. In this regard, Neuroarchitecture is a subject that can be examined within the big framework of Bio. The keyword Risk Simulation is also the topic first presented in the $<$ Advanced Products Utilization $>$ in 2017 and selected in the $<$ Interdisciplinary Subject Integration $>$ in 2018. Thus, the relationships are organic in that the different types can be linked and shared, or distinguished and divided.

Fifth, the field of Social and Emotional Learning(SEL), which first appeared in $<$ Interdisciplinary Subject Integration> in 2018, is highly unique. This is an important social topic associated to human rights issues such as murder or suicide resulting from the disconnection of humancentered relationships, bullying, and witch hunting by the majority. By 2018, <Science-Arts Convergence $>$ was centered on arts. After 2019, the name was changed to $<$ Science, Humanities and Arts Convergence $>$ and the its topic was transferred to solve these social issues from the humanities and social perspective. In addition, it is easy to derive solutions to problems related to social problems by connecting them to $<$ Future Career Connection $>$.

Sixth, the topic of Energy that emerged in 2012 continues onto Future energy in 2015, and Global Environment of the other track ends with Environment. However, with the rise of Ecology in 2017 on the bio track, this can be connected to Environment. In 2015, the topic of Energy and Environment should be an essential topic to examine the global ecological environment and energy resource issues from various aspects.

Seventh, Space series begins with Space Exploration and is divided into three tracks connected by aerospace. One of them, Formation and Evolution of the Earth, led to research specifically focused on the process specializing only about Earth. It is somewhat strange to group abstract topics, like time, together in 2017, but if the formation of the earth is considered as a spatial concept, then the evolution of the earth can be seen as a temporal concept. Space Creation in the second track has separated and continued for 2 years and seems to have disappeared soon, as it is a separate standard that appears naturally on other track. The third track of the universe is Extrasolar Planet, linked by imagination-driven Space Exploration, and continues for four years from 2015-17.

Eighth, mathematic-centered STEAM, as mentioned above, is the intensive study of mathematics in which academic related keyword can be derived not only from $<$ Interdisciplinary Subject Integration $>$, but also from the $<$ Science-Arts Convergence $>$ over the course of two years. It can also be seen that there is somewhat of a weak connection between mathematics and STEAM education. Robotics, which emerged in 2014, has not appeared in $<$ Interdisciplinary Subject Integration $>$ since then, but is stated more specifically in the <Advanced Products Utilization $>$ in the same year and continued until 2016, with its focus on product utilization. In addition, robot technology has been extended to advanced vehicles such as unmanned vehicles, unmanned reconnaissance planes and drones. Therefore, it can be concluded that the topics of $<$ Interdisciplinary Subject Integration $>$ are closely related to $<$ Advanced Products Utilization $>$. As mentioned earlier, the topic of Media and future broadcasting can be categorized as an obsolete topic that never reappears. 
3.3. The Description By Types Without Sub-topics In $<$ interdisci Plinary Subject Integration $>2019-20$

The evolution of the topics of each field of STEAM education, which took place over 8 years, could be reconstructed from various angles. Since 2019, no topic has been presented and replaced with a description according to its type. In the $<$ Interdisciplinary Subject Integration $>$, it is stated to 'suggest a program that can cultivate interest by linking the latest science and technology fields with students' real life and develop the program to show how social issues, current issues, and research trends in the science and technology fields are directly connected to textbooks in which the students learn and to help them to understand that class contents can be related to real life events'. The decision to lift the topic limitations and replace them with explanations is a pleasant surprise for researchers. However, it still may be meaningless to classify the types. The fact that the explanations in <Interdisciplinary Subject Integration> already include science and technology, social and current issues, and what happens in real life should be connected to other subjects is the overall common denominator that must be solved in $<$ Advanced Products Utilization $>$, as well as other types. In thematic aspect, the free topic provided great autonomy to the researcher, but in terms of formality such as the learning framework of STEAM educationsituation presentation, creative design, and emotional experiences [9]- still needs improvement. The threepart STEAM teaching format is still exposed to indoctrination because it is positioned as a timely pressure for teachers to deliver learning content in class, a clear sense of purpose that knowledge should lead to learning, and a mission to deliver wellprepared messages. Potential problems with the form of teaching need to be discussed in-depth with teachers and improved over time.

\section{Development Aspect Of < advanced Products Utilization>}

$<$ Advanced Products Utilization $>$ can be seen as the integration of both <Interdisciplinary Subject Integration $>$ and $<$ Future Career Connection $>$. Table 5 shows the evolution of all the topics presented for $<$ Advanced Products Utilization $>$ in 2012-2018 at a glance. First, among the three keywords presented in 2012 , it is advisory to see the topic of the smartphone as the central topic. The connection continued up from Smart Phone-Tablet PC, ICT Products-Wearable Device, Arduino, to IoT and Cloud. Six years later, it returns back to the Smartphone, because all of the above mentioned technologies can eventually be controlled by this tiny mobile phone. This smartphone, the main topic until 2018, will act as a hub that forms a link with other topics.

First, Digital Cameras that continues towards Advanced Home Appliances in 2014 seems to have been adopted Smartphone in the hub domain. The digital cameras in 2013, expanded from displays, holograms, and 3D cameras in 2015, are consistently progressing to the concept of expanding display devices such as VR gear, AR, and flexible hybrid electronic devices. Indeed, this display technology is a main issue in Wearable Device as well. In 2018, the Wearable Device and Smartphone in the hub domain is re-merged since 2012. This can be interpreted that their close interrelation is with Hybrid Electronic Devices in Display section. However, the robot cleaner, which was presented in 2014, seems to be the only topic that is taking the wrong place.

Second, Internet of Things technology products were introduced in 2014, and the smart house concept, which was introduced as a High-tech House is connected to Smart Home in 2018. From 2015 to 2017 , this topic does not appear to be in progress, but in fact, it includes technologies that are already applied to smart homes in IoT in the central topic. As an extended concept of smart home, it can be connected to smart healthcare, smart life, etc. As an extended concept of Smart Home, it can be connected to smart healthcare, smart life, etc.

Third, in 2013, new vehicle is divided into ground, air, and marine, and its technical products are subdivided. ground vehicle is the extension of autonomous car, and air-marine vehicle clearly divides into two tracks, drone and GPS. The GPS presented first in 2012. Drone includes GPS technology and is presented biennially until 2018 to settle down as locating system product. As one root, the two topics, GPS and New Vehicle, can be summarized as IoT, such as the unmanned reconnaissance plane and unmanned security, which were introduced in the topic of advanced unmanned devices in 2014. It can be found that these three major areas of $<$ Advanced Product Utilization $>$ penetrate the ICT of $<$ Interdisciplinary Subject Integration $>$.

Fourth, Robotics, which was not dealt much in $<$ Interdisciplinary Subject Integration $>$, is linked to robotic prosthetic leg of advanced medical appliances 
Table 5 : Development Aspect of <Advanced Products Utilization $>$ in 2012-18

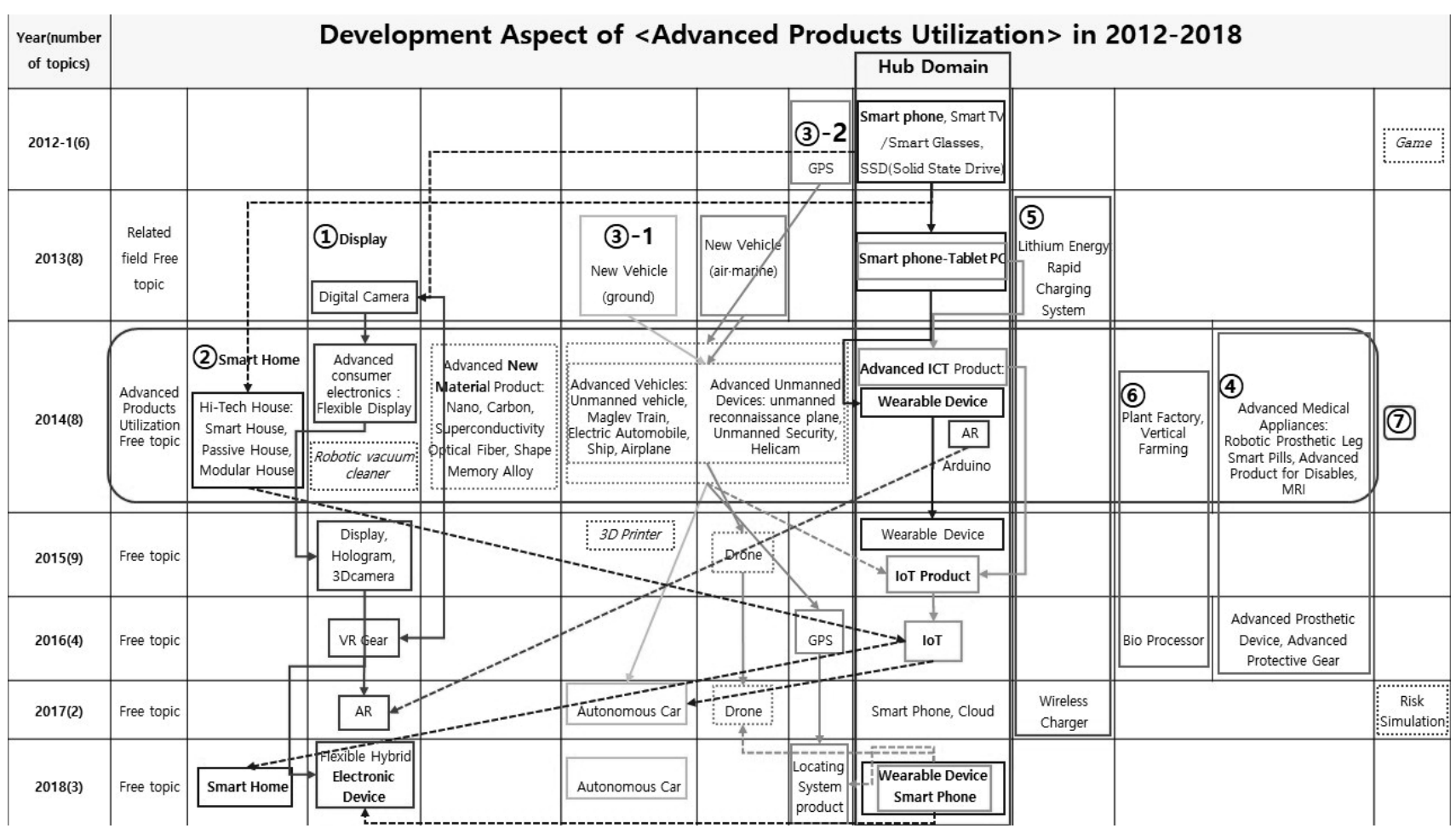

or advanced product for disables, etc. in $<$ Advanced Products Utilization $>$. Topics such as smart pills can be considered in connection with new medicine in 2017 in $<$ Interdisciplinary Subject Integration>.

Fifth, Energy, which was another big branch in $<$ Interdisciplinary Subject Integration $>$, was a topic closely related to the environment, but it can be seen that <Advanced Product Utilization> emphasizes practical energy such as Lithium Energy, Rapid Charging System, and Wireless Charger.

Sixth, while Bio in $<$ Interdisciplinary Subject Integration $>$ connects to sports science and continues toward health and infectious disease, in $<$ Advanced Products Utilization $>$, it starts from plant factory and vertical farming, it continues in 2016 as bio processor. It is appropriate to be placed in <Interdisciplinary Subject Integration $>$, as it is a few topics related to crops that is rarely seen in <Advanced Products Utilization $>$, which focuses mostly on machinery and technology.

Lastly, in <Advanced Products Utilization>, 2014 presents the most dynamic topic. Given specific development requirements, there are more constraints, but this time, the topic wide and diverse, so it is impossible to think that regulation exists. There are unusual topics that are difficult to connect with the topics presented in other years. In advanced new material product, the topic is not about machine or technology, but rather about materials such as Nano, Carbon, Superconductivity Optical Fiber, and Shape Memory Alloy, etc. It is correct to say that these topics should also be dealt with in new material in $<$ Interdisciplinary Subject Integration $>$. As of 2014, it was not even possible to find the right track of what should be placed under a common topic to connect the thinking process.

In addition, Game presented in 2012 is also not suitable for $<$ Advanced Products Utilization $>$. It is a good topic to approach in many different aspects within <Interdisciplinary Subject Integration> or $<$ Science Arts Convergence $>$. In fact, it is appropriate to view the topic in terms of software content rather than the area of products called games. In this context, the above-mentioned Risk Simulation was first presented in 2017 in <Advanced Products Utilization $>$, but the research should continue in the $<$ Interdisciplinary Subject Integration $>$ to have additional experiments. It can be seen that up until 2017 , it is still in the phase of right and left in selecting topics. 
The description of <Advanced Products Utilization $>$ in 2019-20 is somewhat more specific than <Interdisciplinary Subject Integration>. The purpose is to create a program that can provide students with an interesting and easy way to communicate the principles of science and technology embedded in everyday high-tech products such as wearable devices and smartphones. In addition, it states that the purpose is 'to develop a principle and concept included in the curriculum, to interestingly connect with technologies, functions and designs applied to high-tech products, and to present a vision for researching or developing the field.' Through this, it is to use the method of solving the problems that occur during the development of the product, so that the students can experience recognizing and perceiving the related problems as real problems and try to solve them.

The replacement of the proposed topic with a sectoral type explanation would signify that, despite KOFAC's dedication to topic selection, this could in fact create further constraints within the limited topics. If interest is not placed in the content that has been developed because of the overlapping of the principles or sub-topics, while requiring integration by subject, then the current product may still be utilized, but it may not be the high-tech product of tomorrow. It is necessary to go through the process of 'looking again from a different perspective' in order to be able to discover small ideas of creativity and innovation that could develop slow but steady. Given this process, through continuous repetition with frequent failures in a short period of time, other points can be discovered, and at important points, intuition can also be developed to demonstrate decision making ability.

\section{Discussion: Future Topics and Directions for STEAM Education in Korea}

Changes in sub-topics within the types of program development occur in a period of as little as 1 to 2 years and as much as 3 to 4 years. It can be seen that in this periodic change, in the $<$ Interdisciplinary Subject Integration $>$, the two tracks, ICT and Bio, are arranged in the course of the development of $<$ Advanced Products Utilization $>$. The most central topic $<$ Advanced Products Utilization $>$ is wearable devices, Internet of Things, and Smartphones, which change within a common link from the beginning to the present. The subject of $<$ Interdisciplinary Subject Integration $>$ is shared in many areas with the topic of
$<$ Advanced Products Utilization>, but it is also interesting the criteria for distinguishing it is clarified. $<$ Interdisciplinary Subject Integration $>$ is that observation or inquiry is based on principles or theories, and that <Advanced Products Utilization> distinguishes the application and use of actual products with priority. It can also be found that both types can be used to inspire moral problems and moral ethics by linking materials, products, and socioscientific issues used in real life in the arts. In this context, the two types encourage practical experiential learning by connecting the ideas of future career creation or entrepreneurship in social phenomena caused by the development of science and technology.

For the past eight years, the STEAM education program has emphasized the topic-oriented aspect. The types are fixed as in 2019-2020, but it is important to provide opportunities for researchers to select and develop free topics themselves. Science and technology should focus on the connection to solve problems associated with social phenomena. Solving these problems can increase students' ability to cope with the real-world conditions of the work environment in society through the thought process based on the design thinking process. By focusing on human-centered approach and grasping the exact needs of the subject, it is necessary to build consideration and empathy, and to develop divergent and convergent ideas to define the problem. In addition, experiments to create the best results based on the experience of frequent failures while repeatedly reiterating lightweight and fast prototypes should be carried out. In the process of redesigning the perspective and iterating to the previous stage, this process will create innovative ways to solve problems [10].

\section{Conclusion}

The future topics of STEAM education has opened up a wide range of choices so that researchers can freely develop rather than being given. However, the fact that what happens in real life is linked to other subjects to solve problems is the basic concept of STEAM which should be drawn from all types. Each type that demands creativity and innovation is likely to disappear sooner or later, as the requirements themselves describe with similar explanations.

The current development style based on the syllabus outline for instructors is still being continued 
based on the time and development style of the instructor's teaching plan. Instructors should also take the role of guides so that classes can be conducted with free, open-ended questions rather than conventional teaching methods. In particular, science and technology-centered on ICT requires innovation in learning and academic processes through collaboration so that students can create their own questions and understand the answers, just like a class that starts with a question in sole class. Now, it is necessary to introduce and develop instructor's class development, not subject-specific tasks, in the STEAM program. The learning process should be conducted in a free form of discussion, with questions and answers that may cause curiosity. Students should be guided towards self-directed learning that can help find many possibilities for themselves and grasp their perspective, rather than toward problems that can be answered quickly by searching the Internet. Classes should be flexible in time to provide students with team-specific exploration and discussion time. In addition, instructors' intervention must be reduced entirely to avoid indoctrination. In the process of reproducing prototypes, it is the instructor's role to restore the fear of students experiencing frequent failures into encouragements. If the instructors determine in advance the conclusions on the topics to be dealt with in the class, it will inevitably lead to indoctrination or leading questions.

Accordingly, the following program suggests the development conditions to make a new leap forward in Korean STEAM education. First, inventory should be accomplished according to the field or topic. From the perspective of 'rumination', a program capable of reconstructing the problem must be developed. It is somewhat foolish to see many programs developed so far as duplicate topics just because they have been used once. This is because it is important to show the possibility of how the content of the project can change. Second, the modification of the syllabus outline should be derived in accordance with the program development. Moreover, the development of a program that reorganizes the class so that students can form their team and become a collaborationoriented exploration and discussion class should be conducted simultaneously. As a result, teachers would greatly reduce the use of lesson planning. Mainly, the lesson planning is a necessary material for teachers to lead the class. However, for questions asked by unexpected students, a variety of reference materials is the only answer to be prepared. Furthermore, instructors should be involved as a facilitator that guides students with the right questions that can foster curiosity - not the questions that can be answered exactly or right away - and provide a direction during the search process where the questions can be linked to the next question. In other words, the STEAM program should be developed in terms of content and form so that everyone can learn as a researcher, not from the perspective of the roles and functions of students and teachers. Not all programs need to be the same. However, this second proposal states that there must be some programs that need to be changed over time according to the teacher's individual competencies and needs, as well as certain programs that should be maintained. If it is an integrated program that expects creativity and innovation, these two proposals can be expected to take a next big step in the Korean STEAM program.

\section{Acknowledgments}

This research was funded by a 2019 research Grant from Sangmyung University.

\section{References}

[1] Bevins, S. (2012). STEM: Moving the liberal arts education into the 21 st century. Technology and Engineering Teacher, 71(4), p.10-13. Ferraro, D. (2007). W(h)ither liberal education? A modest defense of humanistic schooling in the twentyfirst century. In C. Finn \& D. Ravitch (Eds.), Washington, D.C.: Thomas B. Fordham Foundation.p.25.

[2] KOFAC is a quasi-government and non-profit organization under the Ministry of Science and ICT. https://steam.kofac.re.kr/?page_id=11270.

[3] Lee, S-S. (2020). The development pattern trends for two topics of steam program. International Journal of Education and Learning. Vol.9, No.1, p.35.

[4] Sim, J., Lee, Y., Kim, H. (2015). Understanding STEM, STEAM education, and addressing the issues facing STEAM in the Korean context. Journal of the Korean Association for Science Ed u c a tion, 35 ( 4), p. $709-23$. https://doi.org/10.14697/jkase.2015.35.4.0709.

[5] Lee, S-S. (2020). The development pattern trends for two topics of steam program. International Journal of Education and Learning. Vol.9, No.1, 
p.35-6.

[6] Baek, Y. S., Park, H. J., Kim, Y. M., Noh, S. G., Lee, J. Y., Jeong, J. S., Chio, Y. H., Han, H. S., Choi, J.H. (2012). A Basic Study for Establishing Direction of STEAM. KOFAC. Dec. Research Report.

[7] Lee, S-S. (2020). The development pattern trends for two topics of steam program. International Journal of Education and Learning. Vol.9, No.1, p.38.

[8] Global Challenge Insight Report. "The Future of Jobs: Employment, Skills and Workforce Strategy for the Fourth Industrial Revolution." January 2016. The World Economic Forum. http://www3.weforum.org/docs/WEF_Future_o f_Jobs.pdf.
[9] Kim, Y., Park, N. (2014). The Development of Convergent STEAM Program Focused on Rube Goldberg for Improvement of Engineer Career Awareness of Elementary School Students. Advances in Computer Science and Its Applications: Lecture Notes in Electrical Engineering Vol. 279, CSA 2013. Springer Berlin Heidelberg, 2014. p.429-34.

[10] Brown, T. (2009). Change by Design: How Design Transforms Organizations and Inspires Innovation. New York: Harper Collins Publisher, p.87-108.

[11] Ferraro, D. (2007). W(h)ither liberal education? A modest defense of humanistic schooling in the twenty-first century. In C. Finn \& D. Ravitch (Eds.), Washington, D.C.: Thomas B. Fordham Foundation.p.25. 